\title{
Integration Contracts and Asset Complementarity: Theory and Evidence from US Data*
}

\author{
Paolo Di Giannatale ${ }^{\mathrm{a}, *}$, Francesco Passarelli ${ }^{\mathrm{b}}$ \\ ${ }^{a}$ Nottingham University Business School China, University of Nottingham Ningbo China, 199 Taikang East \\ Road, Ningbo 315100, China \\ ${ }^{b}$ University of Turin, Department of Economics, Esomas, Corso Unione Sovietica, 218 Bis - 10134 Torino, \\ Italy
}

\begin{abstract}
Firms sign integration contracts to increase profits from trade and competition with third parties. An integration contract can improve complementarity among partners (productivity effect) and increase their power in the marketplace (strategic effect). We investigate three bilateral contracts: M\&A, Minority Stake purchase, and Joint Venture. By using a cooperative game approach, we characterize quite general profitability conditions. To estimate the validity of those conditions, we adopt a novel complementarity index. It shows that for any kind of contract, a significant share of the integration profits is due to the "strategic effect" of increased market power. Productivity gains are relatively less important, and in some cases they are negative.
\end{abstract}

JEL classification: C21; C23; C67; C71; G34

Keywords: Cooperative Games; Merger; Acquisition; Joint venture; Complementarity.

\footnotetext{
${ }^{\star}$ We gratefully acknowledge financial support of Collegio Carlo Alberto and Bocconi Baffi-Carefin Center.

*Corresponding author.

Email addresses: Paolo.Di-Giannatale@nottingham.edu.cn (Paolo Di Giannatale), francesco.passarelli@unito.it (Francesco Passarelli)
} 


\section{Introduction}

In the last fifteen years the American Telephone \& Telegraph (AT\&T) corporation, the largest provider of landline phone and broadband television services in the US, has also become the second largest provider of mobile telephone. This position was achieved through a certain number of integration contracts. For instance, in 2000 AT\&T spent $\$$ US1.4 billion to buy a $32 \%$ share of Net2Phone, a software/services company principally specialized in Session Initiation Protocol (SIP)-based and PacketCable-based Voice over Internet Protocol (VoIP) networks. Despite the integration did not lead to the full control of Net2Phone, thereafter AT\&T was able to influence strategically Net2Phone's business with other firms in the telecommunication industry.

In 2003, AT\&T Wireless and Cingular Wireless formed a joint venture (JV) to expand their Global System for Mobile Communications (GSM) and General Packet Radio Service (GPRS) wireless technologies along 3000 miles of interstate highways in Mid-western and Western states which were not covered yet. The two partners had a fifty-fifty control over the JV. At the time, AT\&T and Cingular provided substitutable wireless services. The JV probably dampened detrimental competition among them, and it also reduced strategically the need for further alliances with other competitors.

These two anecdotes suggest that firms might engage in JVs or minority stakes integration (MS) to pursue strategic objective, beyond the mere exploitation of internal synergies. In many cases, this might happen even when the acquisition of full control is a viable option.

An integration contract yields two types of effects. First, a productivity effect, which consists in the improvement or the worsening of the partners' production function. This effect is positive if there are substantial complementarities among their resources (e.g., synergies, better organization, economies of scale). It is negative if joint production gives rise to diseconomies which outweigh complementarities (e.g., organizational issues, misfit of business cultures). Second, a strategic effect, which is due to a change in the partners' market power against competitors, customers, upstream suppliers and other trading parties. Also this 
second effect could be negative, as integration may exacerbate detrimental competition with third parties, or increase their ability to hold up the partners.1 Then it is not obvious that an integration contract guarantees higher profits to the partners.

Using the approach of cooperative games, Segal (2003) is able to provide quite general conditions for the profitability of an M\&A contract. This contract gives one partner the control over $100 \%$ of the other partner's resources. His seminal model, however, is not able to explain why firms often engage in integration contracts and alliances that transfer less than $100 \%$ control over resources. We extend his model in this direction, allowing for MS and JV. Adopting the same cooperative approach we characterize profitability conditions for these forms of integration. We show that, under certain conditions, less than $100 \%$ control is more profitable than the full control over the partner's resources.

Let us illustrate the intuition with an example. Consider three firms in the telecommunication business: $i, j$ and $k$. Firm $i$ provides mobile telephone services using an infrastructure $A$ owned by $k$. Firm $j$ develops and supplies two types of software, $B$ and $C$. Software $B$ is sold to $k$ and to other users, but it is essential to $k$ 's business. Software $C$ is sold to $k$ only, but it is not essential for $k$. Suppose $i$ acquires $100 \%$ control of $j$ : the latter cannot sell software without $i$ 's permission. Suppose there is a positive productivity effect, due to complementarities between $i$ and $j$. But there are also two strategic effects of mutual dependence at work. The first one is positive for the integrating partners: $j$ cannot sell software $B$ to $k$ before $i$ hasn't agreed to rent the infrastructure $A$ from $k$. This effect increases firm $i$ 's ability to hold up $k$.

The second strategic effect is negative: $k$ can threat $i$ not to buy software $C$ if the price paid by $i$ to rent the infrastructure is too low. This second effect increases $k$ 's ability to hold up $i$. The profitability of the acquisition depends on the relative strength of these two

\footnotetext{
${ }^{1}$ An example of increased detrimental competition (with a negative strategic effect) is the "business stealing effect" (Stigler, 1950). When two firms merge, their joint output typically decreases. Competitors operating in the same market (but not taking part in the merger) react by increasing their market shares. As we will show later, the occurrence of such effect depends on the degree of substitutability between the competitors' resources and the resources of integrating partners.
} 
effects. However, the two partners can do better than the full acquisition. Suppose $i$ and $j$ sign a MS contract which gives the former the control over software $B$ only. Thus, $j$ can sell software $C$ independently of $i$, with the consequence that $k$ 's ability to hold up $i$ does not increase. It is apparent that the MS allows the partners to make more profits than the full acquisition.

As mentioned earlier, strategic effects are negative when integration increases detrimental competition with third parties. To see it, suppose that, in addition to what has been described above, firm $k$ and firm $j$ sell a similar product in market $D$. They are substitutable in that market. Suppose $i$ acquires $100 \%$ of $j$, but it is not able to supply market $D$ until it has rented infrastructure $A$. This gives $k$ the chance to "steal" part of market $D$. In a way, this happens because $i$ 's full control over $j$ 's resources lowers the substitutability between $j$ and $k$ in market $D$. Also in this case a MS contract that gives $j$ the ability to supply market $D$ independently of $i$ would perform better than the full acquisition.

Segal (2003) shows that an M\&A contract which assigns partner $i$ the full control over $j$ 's resources is profitable if, in the presence of $i$, the complementarity of third parties with $j$ 's resources is lower. The reason is that when $i$ controls $j$ 's resources third parties' hold-up power is lower. Similarly, if in the presence of $i$ the substitutability between $j$ and third parties increases, then integration is profitable. The reason being that letting $i$ control j's resources lowers detrimental competition with third parties. The theoretical model in this paper reformulates Segal's condition, saying that an M\&A contract is profitable if the complementarity of third parties with the joint resources of $i$ and $j$ is lower than the sum of third parties' complementarity with $i$ and $j$, separately $\left.\right|^{2}$ Our model provides profitability conditions also for MS and JV contracts.

We claim that whenever the profitability conditions are satisfied, gains from integration are higher, and we find support in the data. Our empirical goal is testing the effect of

\footnotetext{
${ }^{2}$ Hereafter, we will refer to substitutability as the case where complementarity is negative. Thus, if complementarity is negative, "lower (higher) complementarity" implies that substitutability is higher (lower).
} 
changing the complementarity structure of firms on the post-integration profits. Thus our empirical strategy is the following. First, we assume that firms choose a certain type of integration unaware of the changes in complementarities possibly caused by the contract. Namely, we assume that the choice of a contract is not affected by profitability conditions whose validity has not been tested yet. Second, we measure the average impact on profits in all cases where the changes in complementarity satisfy those conditions, and we find support.

An additional contribution of this paper is in the definition of an index to measure resource complementarity among firms. It addresses a measurement complexity issue arising from the fact that firms are usually involved in different businesses, each of them belonging to different sectors. The index accounts for dynamic complexity, due to the fact that complementarity between pairs of industrial sectors changes over time as a result of new products and/or technologies.

In order to build the complementarity index and test theoretical predictions, we use Orbis and Zephyr databases (Bureau Van Dijk) which refer to 8106 US listed companies that signed an integration contract in the period 2002-2007. Contracts involved companies operating in 90 different primary industrial sectors.

In the cases of full acquisition (M\&A), partners' profits increase on average by $4.49 \%$ for any increase in the complementarity index between acquiror and third parties and by $0.37 \%$ for a decrease in the complementarity between target and third parties. This means that the strategic effect is positive. As for the productivity effect, data show that return on assets falls down by $4.33 \%$ if the integration is associated with an increase in the complementarity index between the partners. Thus the productivity effect is negative when controlling for the strategic effect. This supports the idea that in many cases M\&As are motivated by the objective of strategically gaining market power rather than gaining efficiency.

A MS gives partner $i$ the ability to control a share $\lambda$ of $j$ 's resources $(\lambda<1 / 2)$. Data show that profits increase on average by $1.51 \%$ from a minority partnership if the profitability condition is satisfied. Additional $4.58 \%$ occur for each decrease in $j$ 's complementarity with 
third parties. As in the case of an M\&A, complementarity between partners has a negative effect on profits $(-4.7 \%)$. The model shows that a MS is preferable to an M\&A if the complementarity of third parties with $i$ and the controlled share of $j$ 's resources is smaller than their complementarity with $i$ and $j$ 's resources as a whole $3^{3}$ In our data, all other things being equal the average performance of a MS is $3.6 \%$ higher than an M\&A.

A JV gives rise to a new independent entity, endowed with an amount of resources conferred by the partners on the basis of equity shares. The theoretical profitability condition says that a JV is profitable if the complementarity of third parties with the new entity is lower than their complementarity with the conferred resources separately. In other words, a JV is profitable if allowing the JV to control the conferred resources as a whole implies that third parties lose part of their hold-up power (or their ability to "steal" shares of the partners' market).

Data show that, if the profitability condition is satisfied, a JV yields an average increase of $2.2 \%$ in return on assets - an even higher effect compared to a MS. In addition, profits increase $(+3.5 \%)$ if the partner's complementarity with third parties is higher (or substitutability is lower). This provides an evidence of a strong strategic effect. Differently from the other two contracts, the productivity effect of a JV is positive $(+2.5 \%)$, but smaller in size compared to the strategic effect.

These empirical findings suggest two general results. First, contracts which transfer less than full control of a partner's resources on average have a larger positive impact on the partners' joint profits. Second, the relative importance of the strategic effect is larger for this kind of contracts.

The cooperative game approach to integration contracts dates back to the seminal works of Grossman and Hart (1986) and Hart and Moore (1990), who, in contrast to the Coasian logic, focussed on limits to contractibility. They showed that changing the ownership of

\footnotetext{
${ }^{3}$ In case of substitutability, a MS is more profitable than an M\&A if the substitutability of third parties with $i$ and the controlled share of $j$ 's resources is higher than their substitutability with $i$ and $j$ 's resources as a whole.
} 
a collection of assets affects bargaining power, and then the distribution of surplus. This yields two effects. First, given ex-post efficiency, the owners can capture a larger share of ex-post surplus. Second, the prospect of a larger share leads the agents to undertake non-contractible actions ex-ante, which in turn may prompt ex-post efficiency. Relatedly, the enormous literature originated by Grossman and Hart's works can be split in two big strands. The first strand studies how ownership structures provide appropriate incentives to ex-ante investments that enhance efficiency $\left.\right|^{4}$ The present paper belongs to a second strand, that is mainly focused on exploring how integration contracts or partnerships occurring prior to production, affect final allocations resulting from bargaining with common third parties (e.g., Davidson, 1988; Horn and Wolinsky, 1988; Chipty and Snyder, 1999; Stole and Zwiebel, 2008; Elliott, 2015). The most related work is Segal (2003). He provides a very general framework to study how substitutability/complementarity of integrating partners affects their ability to hold-up third parties. As mentioned earlier, we build on his work, allowing for collusion contracts that transfer less than full control.

The idea that partners that acquire a minority stake can exert some degree of influence on the target firm ties our work to the corporate finance literature that studies the power of minority shareholding. Bhagat and Brickley (1984) show that minorities are able to influence the election of some board members even if the majority opposes their election $5^{5}$ Butz (1994) points to the fact that minorities are influential because they can threat the CEO to purchase more shares in order to acquire majority control. Ciccotello and Hornyak (2000) study the minority's power in joint ventures. Elfenbein and Lerner (2012) show that the allocation of property rights is chosen according to the relative bargaining power, and how it may lead to increased performance of the partners. These contributions belong to a wider mainstream literature exploring how the allocation of ownership rights influences the performance of

\footnotetext{
${ }^{4}$ For a recent and comprehensive survey, see Legros and Newman (2014).

${ }^{5}$ Often minorities vote on key managerial decisions such as mergers and acquisitions (Bethel et al., 2009), thus investors may acquire voting rights just to influence the outcome of M\&A proposals (Hu and Black, 2007).
} 
the alliances (see Kloyer, 2011; Bodnaruk et al., 2013; Haeussler and Higgins, 2014; Prange and Mayrhofer, 2015 for an overview). Differently from us, this literature focusses on the minority-majority relationship within the firm. We study minority shareholdings' effects outside the firm. Namely, we study the effects on "horizontal" competition with other firms, and the effect on "vertical" trade with suppliers and customers.

The paper is organized as follows. Section 2 presents the cooperative game model to study integration contracts, and characterizes profitability conditions. Section 3 introduces the complementarity index. Section 4 presents the database and some descriptive statistics. Section 5 tests theoretical predictions. Section 6 concludes.

\section{Model}

Let $N=\{1, \ldots, n\}$ be a set of agents in the game. Agents can be firms competing in the same sector, firms in the upstream or downstream sectors, and customers. Let $2^{N}$ denote the set of all possible subsets of agents. They own perfectly divisible and summable assets $A=\left\{a_{1}, \ldots, a_{n}\right\}$ with control structure $C(S) \in \mathbb{C}$, where $\mathbb{C}$ is the set of all mappings from $2^{N}$ to $\mathbb{R}^{|S|}$. The set function $C(S)$ defines the assets controlled by the subset $S$ of agents. We will refer sometimes to $S$ as a coalition of agents.

To illustrate how $C(S)$ defines the assets controlled by coalition $S$, take for instance $S=\{i, j\}$ (with $i, j \in N$ ). Let $\lambda_{i}^{h}$ be the share of agent $h$ 's assets controlled by agent $i$, and let $\lambda_{j}^{h}$ be the share of agent $h$ 's assets controlled by agent $j,(h=1, . ., n)$. Therefore, $C(\{i, j\})=\left\{\sum_{h \in N} \lambda_{i}^{h} a_{h}, \sum_{h \in N} \lambda_{j}^{h} a_{h}\right\}$ with $\sum_{h \in N} \lambda_{k}^{h}=1$ for all $k \in N$.

Let $(N, v)$ be a game with characteristic function $v(S, C(S)): 2^{N} \times \mathbb{C} \rightarrow \mathbb{R}$, for any coalition $S \subseteq N$. An integration contract has the effect of changing the control structure of the game. In order to simplify notation, let $v(S, C(S)) \equiv v^{C}(S)$.

The timing of events is the following. At period 0 two players, $i$ and $j$, sign an integration contract. At period 1 all players play the game and split total payoffs according to the following solution. 
Let $p^{i}(S)$ be the probability of any coalition $S$ not containing $i$,

Definition 1. Weber, 1988) A solution $\phi\left(v^{C}\right)=\left\{\phi_{1}\left(v^{C}\right), . ., \phi_{n}\left(v^{C}\right)\right\}$ is a probabilistic value of game $v^{C}$ if for all $i$

$$
\phi_{i}\left(v^{C}\right)=\sum_{S \in 2^{N} \backslash i} p^{i}(S) \Delta_{i} v^{C}(S)
$$

with $\Delta_{i} v^{C}(S)=\left[v^{C}(S \cup i)-v^{C}(S)\right]$, and $i=1, \ldots, n$.

The idea is that each player enters the negotiation arena at random with the scope of forming a coalition. Producing, and exchanging with other players implies forming a coalition with them. A coalition $S$ is random because players are supposed to enter a coalition at random. The probability of any coalition $S$ not containing $i$ is $p^{i}(S)$ and it can be derived from the entry probability distributions of all players ${ }^{6}$ A probabilistic value assigns each player her/his expected marginal contribution to the random coalition $S$. If for instance the value (in dollars) of coalition $S$ increases by $\Delta_{i} v^{C}(S)=\$ 5$ when player $i$ joins that coalition, and the probability of forming that coalition is $p^{i}(S)=25 \%$, then player $i$ expects to be rewarded by $\$ 1.25$. By randomizing over all coalitions one obtains total expected rewards

\footnotetext{
${ }^{6}$ Specifically, call $x_{j}(t)$ the probability that player $j$ has entered by time $t \in[0,1],(j \in N)$. The probability that player $i$ joins a coalition $S \subseteq N \backslash i$, at time $t$, is:

$$
\prod_{\substack{j \in S \\ S \subseteq N \backslash i}} x_{j}(t) \prod_{\substack{j \notin S \\ S \subseteq N \backslash i}}\left(1-x_{j}(t)\right) \cdot x_{i}^{\prime}(t)
$$

and player $i$ expects to join coalition $S$ with probability:

$$
p^{i}(S)=\int_{0}^{1} \prod_{\substack{j \in S \\ S \subseteq N \backslash i}} x_{j}(t) \prod_{\substack{j \notin S \\ S \subseteq N \backslash i}}\left(1-x_{j}(t)\right) d x_{i}(t)
$$

Functions $x_{j}(t)$ represent players' attitudes to enter a coalition "early" or "late" (cf. Owen, 1972, and Monderer and Samet, 2002). One might think of $x_{j}(t)$ as a proxy of $j$ 's attitudes during the negotiations that lead to the formation of a coalition.

If the entry functions, $x_{j}(t)$, are different then $p^{i}(S)$ may depend on the identities of the members in $S$. The idea is that when players have different attitudes, the probability to form a coalition $S$ depends on "who" are the players in it.

If all entry probabilities are uniform in [0,1] (i.e., $x_{j}(t)=t$ for all $j \in N$ ) then $p^{i}(S)=\frac{s !(n-s-1) !}{n !}$ (with $s=|S|, S \subseteq N$ ) and (1) is the Shapley Value. In this case players behave symmetrically during negotiations. Thus, for any $S$, the probability $p(S)$ does not depend on the "identities" of the players in $S$. It can only depend on the number of members, $|S|$.

Finally, observe that $p^{i}(S)$ does not depend on $v^{C}$.
} 
of player $i$, i.e. $\phi_{i}\left(v^{C}\right)$. A division rule based on the probabilistic value is very general. It is descriptive of a large variety of situations in which players expect to split the value of their cooperation according to some "reasonable" assumptions. It can be characterized axiomatically, where the axioms correspond to those assumptions.7 Therefore, the results in this paper are quite general. Most of them are not robust to alternative division rules which are not probabilistic values. However, such alternative rules would break, at least partially, those reasonable assumptions.

Ichiishi (1993) uses the second-order difference operator, $\Delta_{k i}^{2} v^{C}(S)=\Delta_{k} v^{C}(S \cup i)-$ $\Delta_{k} v^{C}(S)$, to measure complementarity between $i$ 's and $k$ 's assets. Throughout the paper we will need to measure complementarity between $k$ 's assets and those under the control of a generic coalition $G$. Thus we define:

Definition 2. $\Delta_{k G}^{2} v^{C}(S)$ represents the complementarity between player $k$ and the members of coalition $G$, where $\Delta_{k G}^{2} v^{C}(S)=\Delta_{k} v^{C}(S \cup G)-\Delta_{k} v^{C}(S)$, (with $k \in N, G, S \subseteq N \backslash k$ and $S \cap G=\emptyset)$.

Roughly speaking, $k$ is complementary to the members of $G$ if $k$ 's resources are more valuable whenever also $G^{\prime}$ 's resources are used. In this case, $\Delta_{k G}^{2} v^{C}(S)>0$. Complementarity goes in both directions. It also implies that the value jointly added by members of $G$ to any other coalition $S$ is higher in the presence of player $k$. If instead the value added by $k$ decreases when $G^{\prime}$ 's resources are used, then the complementarity between $k$ and $G$ is negative: $\Delta_{k G}^{2} v^{C}(S)<0$. We also say in this case that $k$ is substitute of $G$.

An integration contract between $i$ and $j$ changes the control structure of their assets, giving $i$ the control of a share $\lambda_{i}^{j}$ of $j$ 's resource $a_{j}$. Of course, a variety of integration contracts may occur amongst subsets of agents. Here, we will consider only the effect of

\footnotetext{
${ }^{7}$ Weber (1988) shows that, for a game $v$, a probabilistic value satisfies linearity, dummy and monotonicity axioms. Linearity implies that a rational agent playing a game $v w($.$) , such that v w()=.v()+.w($.$) , well$ considers to receive from $v w($.$) the sum of gains he would receive from the two original games, v($.$) and w($.$) .$ The dummy axiom implies that if a player $i$ contributes any coalition just $v(i)$ then he will receive $v(i)$. Monotonicity requires that any player $i$ never "hurts" any coalition $S: \Delta_{i} v(S) \geq 0$. Weber's results apply to any game $v^{C}$ with general control structure $C(S)$, as defined in the present paper.
} 
contracts between two agents, $i$ and $j$, holding constant the control over the resources of other agents. Thus, for simplicity $\lambda_{i}^{j}=\lambda \in(0,1]$. Formally:

$C_{i, j}^{\lambda}(S) \in \mathbb{C}$ is an integration contract between $i$ and $j$ that transfers a share $\lambda$ of $j$ 's assets under $i$ 's control if for any $S \subseteq N \backslash i \backslash j$

$$
\begin{gathered}
C_{i, j}^{\lambda}(S)=\left(a_{k}\right)_{k \in S} \\
C_{i, j}^{\lambda}(S \cup i)=\left(a_{k}\right)_{k \in S} \cup\left\{a_{i}+\lambda a_{j}\right\} \\
C_{i, j}^{\lambda}(S \cup j)=\left(a_{k}\right)_{k \in S} \cup\left\{(1-\lambda) a_{j}\right\} \\
C_{i, j}^{\lambda}(S \cup i \cup j)=\left(a_{k}\right)_{k \in S} \cup\left\{a_{i}+\lambda a_{j},(1-\lambda) a_{j}\right\}
\end{gathered}
$$

Let $v^{C_{0}}(S)$ denote the pre-integration game, and let $v^{C_{i, j}^{\lambda}}(S)$ be the game after the integration contract between $i$ and $j$. Differently from Segal (2003), the above definition can describe situations in which partner $i$ acquires less than the full control of $j$ 's resources, a situation that typically occurs in minority stakes contracts. As in his model, an integration contract is profitable if it reduces all other players' expected payoffs:

$$
\phi_{k}\left(v^{C_{i, j}^{\lambda}}\right)-\phi_{k}\left(v^{C_{0}}\right)<0
$$

for any $k \neq i, j$. If $\lambda=1$, our definition coincides with Segal's.

\subsection{M\&A contracts}

An M\&A is a contract that assigns firm $i$ the total control of $j$ 's resources. Thus $\lambda=$ 1. Let $v^{C_{i, j}^{\lambda=1}}(S) \equiv v^{M \& A}(S)$. Through an M\&A, player $i$ can manage $j$ 's resources even in the absence of $j$. The complete $\$ 1.2 \mathrm{~B}$ acquisition of Leap Wireless (the target $j$ ) by AT\&T (the acquiror $i$ ) in 2014 is an example of M\&A. As pointed out earlier, this is the collusion contract studied by Segal. As mentioned earlier, he showed that a collusion contract (i.e., an M\&A) is profitable if for any third player $k$, the presence of player $i$ lowers the

complementarity between $k$ and $j$ (Segal, 2003, p. 449). In the following proposition we show that his profitability condition, which is based on the sign of a third-difference term, 
can be reformulated as a comparison between two terms. First, the complementarity between $k$ and the two partners, taken jointly. Second, the sum of the complementarity measures between $k$ and the two partners, separately. We make this reformulation in order to get an empirically testable statement in which Segal's condition is expressed as the sum of two second differences.

Proposition 1. An $M \& A$ between $i$ and $j$ is profitable if in the pre-integration game $v^{C_{0}}$ all third parties $k$ are less complementary to $G=\{i, j\}$ than to $i$ and $j$, separately: $\Delta_{k\{i, j\}}^{2} v^{C_{0}}(S)<$ $\Delta_{k i}^{2} v^{C_{0}}(S)+\Delta_{k j}^{2} v^{C_{0}}(S)$, for all $k$ and all $S$.

Proof. An M\&A contract affects the worth of those coalitions that contain only one of the integrating parties. As regards players' marginal contributions, they are affected in the following way:

1. Firm $j$ becomes a null player in all coalitions.

2. Firm $i$ contributes more than before to all coalitions, because it brings $j$ 's resources.

3. Player $k$ 's marginal contributions are the following:

$$
\Delta_{k} v^{M \& A}(S)=\left\{\begin{array}{c}
\Delta_{k} v^{C_{0}}(S \backslash j) \text { for any } S \subseteq N \backslash i \cup j \\
\Delta_{k} v^{C_{0}}(S \cup j) \text { for any } S \subseteq N \backslash j \cup i \\
\Delta_{k} v^{C_{0}}(S) \text { otherwise }
\end{array}\right.
$$

The first line represents the "exclusion" effect of collusion described by Segal (2003, p. 445). The second line is the "inclusion" effect (p. 447). The former occurs because player $j$ 's resources are excluded from coalitions that do not contain $i$. The latter occurs because player $i$ brings $j$ 's resources also when $j$ has not joined a coalition yet. Thus we can write the variations in player $k$ 's marginal contributions:

$$
\Delta_{k} v^{M \& A}(S)-\Delta_{k} v^{C_{0}}(S)=\left\{\begin{array}{c}
\Delta_{k} v^{C_{0}}(S \backslash j)-\Delta_{k} v^{C_{0}}(S) \text { for any } S \subseteq N \backslash i \cup j \\
\Delta_{k} v^{C_{0}}(S \cup j \cup i)-\Delta_{k} v^{C_{0}}(S \cup i) \text { for any } S \subseteq N \backslash j \cup i \\
0 \text { otherwise }
\end{array}\right.
$$


which can also be written as

$$
\Delta_{k} v^{M \& A}(S)-\Delta_{k} v^{C_{0}}(S)=\left\{\begin{array}{cl}
-\Delta_{k j}^{2} v^{C_{0}}(S) & \text { for any } S \subseteq N \backslash i \cup j \\
\Delta_{k j}^{2} v^{C_{0}}(S \cup i) & \text { for any } S \subseteq N \backslash j \cup i \\
0 & \text { otherwise }
\end{array}\right.
$$

To understand (3), suppose $k$ and $j$ are complementary (i.e., $\Delta_{k j}^{2} v^{C_{0}}(S)>0$ ). The first line in the RHS of (3) is a positive effect for $i$ and $j$. It tells us that $k$ 's marginal contributions to coalitions that include $j$ (and not $i$ ) decrease because now $k$ has to "wait for $i$ ". The second line is a negative effect for $i$ and $j$. It says that $k$ 's marginal contributions to coalitions that include $i$ (and not $j$ ) increase, because now $i$ has already brought $j$ 's resources. Thus $k$ 's contribution is larger. If $k$ and $j$ are substitutable (i.e., $\Delta_{k j}^{2} v^{C_{0}}(S)<0$ ), the second line represents a positive effect for the two partners while the first line is a negative. The interpretation hinges on the fact that the M\&A reduces detrimental competition between $j$ and $k$, but it also gives the latter the chance to steal part of the partners' market.

The M\&A is profitable if the first effect is larger than the second one, for all $k$ and all $S$ :

$$
\Delta_{k j}^{2} v^{C_{0}}(S \cup i)-\Delta_{k j}^{2} v^{C_{0}}(S)<0
$$

In this case, (2) is satisfied for all $k(\lambda=1)$. Let us re-write (4) as

$$
\Delta_{k} v^{C_{0}}(S \cup\{i, j\})-\Delta_{k} v^{C_{0}}(S \cup j)-\left[\Delta_{k} v^{C_{0}}(S \cup i)-\Delta_{k} v^{C_{0}}(S)\right]<0
$$

Adding the zero-sum term $\Delta_{k} v^{C_{0}}(S)-\Delta_{k} v^{C_{0}}(S)$ and rearranging, yields

$$
\Delta_{k\{i, j\}}^{2} v^{C_{0}}(S)<\left[\Delta_{k i}^{2} v^{C_{0}}(S)+\Delta_{k j}^{2} v^{C_{0}}(S)\right]
$$

which must be true for any $k \neq i, j$ and all $S \subseteq N \backslash i \backslash j \backslash k$. 
The complementarity between $i$ and $j$ is not sufficient to ensure profitability of an M\&A contract. A sufficient condition is that (5) is satisfied for all $k$. To see the intuition, suppose the two partners are complementary. They are more efficient when they merge (i.e., the productivity effect is positive). However, it is perfectly possible either that the complementarity of $k$ 's resource increases giving $k$ a larger hold-up power, or the substitutability to $k$ decreases, giving $k$ more market power (e.g., business stealing effect). In other words, it is possible that $k$ 's resource becomes more "essential" to the partners or less substitutable from the customers' viewpoint. If this occurs for all $k$, the strategic effect is negative and an M\&A results in a loss of market power that may jeopardize the benefits of integration. Finally observe that proposition 1 does not require players to have symmetric attitudes during negotiations. It holds for any solution that is a probabilistic value $]^{8}$

\subsection{Minority stakes contracts}

Through an integration contract, firm $i$ acquires the control of a share $\lambda a_{j}$ of $j$ 's assets $(\lambda \leq 1)$. If $0<\lambda<0.5$, we say that the contract consists in a minority stakes integration. A MS contract typically occurs when $i$ is a minority shareholder of $j$, as in the case of AT\&T buying $32 \%$ of Net2Phone in 2000 . As pointed out earlier, minority shareholders exert a certain amount of influence on the target's decision. With a high level of generality, we parametrize $i$ 's decisional influence through the probability, $\sigma$, that $i$ brings all $j$ 's resources with him when he enters any coalition $S$. More precisely, suppose $i$ enters a coalition $S \subseteq$ $N \backslash i \backslash j$. With probability $\sigma$, he adds $\left\{a_{i}, a_{j}\right\}$ to all resources available to that coalition, whereas with probability $1-\sigma$ he adds "only" $\left\{a_{i}, \lambda a_{j}\right\}$. Realistically, the amount of influence $\sigma$ that a minority shareholder exerts on target $j$ positively depends on the share size, $\lambda 9^{9}$

Proposition 2 below says that a MS contract is profitable if it lowers the complementarity

\footnotetext{
${ }^{8} \mathrm{Cf}$. footnotes 6 and 7 above. Later it will become apparent that also propositions $2-4$ do not require symmetry.

${ }^{9}$ Of course, $i$ 's decisional influence can also depend on other factors, such as the level of fractionalization of the other shareholders, or the credibility of $i$ 's threat to sell $\lambda a_{j}$ to some opponent of $j$ 's majority shareholder (cf. Butz, 1994 and Hubbard and Palia, 1995).
} 
of third parties' resources with $\lambda a_{j}$. In this case, the strategic effect of a MS integration is positive, because it makes third parties less essential to the partners.

Proposition 2. A minority stakes contract between $i$ and $j$ is profitable if in the preintegration game $v^{C_{0}}$ any third party's resource $a_{k}$ is less complementary to $\left\{a_{i}, \lambda a_{j}\right\}$ than to $a_{i}$ and $\lambda a_{j}$, separately.

Proof. Let $v^{M S}(S)$ denote the post-integration characteristic function. Because of a minority stakes contract, $k$ 's expected contributions become

$$
\left\{\begin{array}{l}
\Delta_{k} v^{M S}(S)=\sigma \Delta_{k} v^{C_{0}}(S \cup i \cup j)+(1-\sigma) \Delta_{k} v^{C_{0}}\left(S \cup i \cup j^{\lambda}\right) \text { with } S \cup i \\
\Delta_{k} v^{M S}(S)=\sigma \Delta_{k} v^{C_{0}}(S)+(1-\sigma) \Delta_{k} v^{C_{0}}\left(S \cup j^{1-\lambda}\right) \text { with } S \cup j
\end{array}\right.
$$

for any $S \subseteq N \backslash i \backslash j \backslash k$, where $S \cup i \cup j^{\lambda}$ is a coalition $S$ in which $i$ brings also $\lambda a_{j}$, and $S \cup j^{1-\lambda}$ is a coalition $S$ in which $j$ brings only the share $(1-\lambda) a_{j}$ of his own resources. The expected variation in $k$ 's payoff is

$$
\begin{gathered}
\sigma\left[\Delta_{k} v^{C_{0}}(S \cup i \cup j)-\Delta_{k} v^{C_{0}}(S \cup i)\right]+(1-\sigma)\left[\Delta_{k} v^{C_{0}}\left(S \cup i \cup j^{\lambda}\right)-\Delta_{k} v^{C_{0}}(S \cup i)\right] \\
+\sigma\left[\Delta_{k} v^{C_{0}}(S \backslash j)-\Delta_{k} v^{C_{0}}(S \cup j)\right]+(1-\sigma)\left[\Delta_{k} v^{C_{0}}\left(S \cup j^{1-\lambda}\right)-\Delta_{k} v^{C_{0}}(S \cup j)\right] \\
\quad=\sigma\left[\Delta_{k j}^{2} v^{C_{0}}(S \cup i)-\Delta_{k j}^{2} v^{C_{0}}(S)\right]+(1-\sigma)\left[\Delta_{k j^{\lambda}}^{2} v^{C_{0}}(S \cup i)-\Delta_{k j^{\lambda}}^{2} v^{C_{0}}\left(S \cup j^{1-\lambda}\right)\right]
\end{gathered}
$$

Replacing the difference $\Delta_{k j}^{2} v^{C_{0}}(S \cup i)-\Delta_{k j}^{2} v^{C_{0}}(S)$ with the terms in (5) and requiring (2), we get:

$$
\Delta_{k j^{\lambda}}^{2} v^{C_{0}}(S \cup i)-\Delta_{k j^{\lambda}}^{2} v^{C_{0}}\left(S \cup j^{1-\lambda}\right)<\frac{\sigma}{\sigma-1}\left[\Delta_{k\{i, j\}}^{2} v^{C_{0}}(S)-\Delta_{k i}^{2} v^{C_{0}}(S)-\Delta_{k j}^{2} v^{C_{0}}(S)\right]
$$

for all $S \subseteq N \backslash i \backslash j \backslash k$ and any $k \in N \backslash i \backslash j$. Let us denote the LHS of (6) by $y$ and the difference in square brackets of RHS by $x$. The MS contract is profitable if

$$
y<\frac{\sigma}{\sigma-1} x
$$


By $0<\sigma<1$ it follows that $\frac{\sigma}{\sigma-1}<0$. Thus inequality (7) is satisfied if $y \leq 0$, or equivalently, if

$$
\Delta_{k j^{\lambda}}^{2} v^{C_{0}}(S \cup i)<\Delta_{k j^{\lambda}}^{2} v^{C_{0}}\left(S \cup j^{1-\lambda}\right)
$$

By proposition 2, the profitability of a MS contract is independent of $i$ 's decisional influence, $\sigma$. Eventually, $\sigma$ affects the size of profits change, but not the sign of that change. The profitability of a MS is linked to the reduction of third parties' complementarity with the acquired share $\lambda a_{j}$, when the latter is used jointly with $a_{i}$. The intuition is the same as in proposition 1. Parties become less essential or more substitutable, leading to a strategic increase of partners' market power.

It is perfectly plausible that third parties become less essential or more substitutable when $i$ acquires the share $\lambda a_{j}$, whereas this would not happen should $i$ acquire the whole $a_{j}$. In general, a MS contract can be more profitable than an M\&A because it allows to integrate exactly those assets that yield a larger "strategic" effect. The following proposition makes this point, formally.

Proposition 3. A minority stakes contract between $i$ and $j$ is more profitable than an $M \& A$ contract if complementarity between $k$ 's assets and $\left\{a_{i}, \lambda a_{j}\right\}$ is lower in the absence of $j$ 's non-integrated resources, $(1-\lambda) a_{j}$, than in the presence of these resources.

Proof. Consider $x, y$ in (7) and let $x<0$ (an M\&A would be profitable). Then, a MS contract is preferable if the externality that it yields on any $k$ is larger than the externality produced by M\&A, which yields

$$
(1-\sigma) y+\sigma \cdot x<x \Longrightarrow y<x<0
$$

Inequality (9) implies

$$
\Delta_{k j^{\lambda}}^{2} v^{C_{0}}(S \cup i)-\Delta_{k j^{\lambda}}^{2} v^{C_{0}}\left(S \cup j^{1-\lambda}\right)<\Delta_{k\{i, j\}}^{2} v^{C_{0}}(S)-\Delta_{k i}^{2} v^{C_{0}}(S)-\Delta_{k j}^{2} v^{C_{0}}(S)
$$


or equivalently

$$
\begin{aligned}
& \Delta_{k} v^{C_{0}}\left(S \cup i \cup j^{\lambda}\right)-\Delta_{k} v^{C_{0}}(S \cup i)+\Delta_{k} v^{C_{0}}\left(S \cup j^{1-\lambda}\right)-\Delta_{k} v^{C_{0}}(S \cup j) \\
< & \Delta_{k} v^{C_{0}}(S \cup\{i, j\})-\Delta_{k} v^{C_{0}}(S)-\Delta_{k} v^{C_{0}}(S \cup i)+\Delta_{k} v^{C_{0}}(S)+\Delta_{k} v^{C_{0}}(S)-\Delta_{k} v^{C_{0}}(S \cup j)
\end{aligned}
$$

Rearranging the above inequality, we have

$$
\Delta_{k\left\{i, j^{\lambda}\right\}}^{2} v^{C_{0}}(S)<\Delta_{k\left\{i, j^{\lambda}\right\}}^{2} v^{C_{0}}\left(S \cup j^{1-\lambda}\right)
$$

for all $k \in N \backslash i \backslash j$ and $S \subseteq N \backslash i \backslash j \backslash k$.

Proposition 3 provides a theoretical explanation of our empirical result that MS contracts have on average a larger positive impact on profits than M\&A contracts.

\subsection{JVs with joint ownership}

Suppose two parent firms, $i$ and $j$, confer an equal share $\lambda$ of their resources to form a JV. We assume that the control of the JV's resources is assigned to $i$ or $j$ with equal probability. This reflects the idea that each player has a fifty-fifty influence on JV's decisions. The strategic effect of a JV is positive if it either reduces third parties' ability to hold-up any of the two parents, or it increases their substitutability with the parent firms from the customers' viewpoint. Formally,

Proposition 4. A JV contract between $i$ and $j$ is profitable if it lowers third parties' complementarity with $\left(a_{l}+\lambda a_{m}\right)$, where $l, m=i, j$ and $l \neq m$.

Proof. The JV becomes the $(n+1)$ th player in the game. The new control structure implies the existence of an additional player. A coalition of all players including the new entity is such that

$$
C_{i, j}^{\lambda}(N \cup(n+1))=\left\{a_{1}, \ldots, a_{i}(1-\lambda), \ldots,(1-\lambda) a_{j}, \ldots, a_{n}, \lambda\left(a_{i}+a_{j}\right)\right\}
$$

By the JV contract, $k$ 's expected contributions are 


$$
\left\{\begin{array}{l}
\Delta_{k} v^{J V}(S)=\left[\Delta_{k} v^{C_{0}}\left(S \cup i \cup j^{\lambda}\right)+\Delta_{k} v^{C_{0}}\left(S \cup i^{1-\lambda}\right)\right] / 2 \text { with } S \cup i \\
\Delta_{k} v^{J V}(S)=\left[\Delta_{k} v^{C_{0}}\left(S \cup j \cup i^{\lambda}\right)+\Delta_{k} v^{C_{0}}\left(S \cup j^{1-\lambda}\right)\right] / 2 \text { with } S \cup j
\end{array}\right.
$$

where player $j^{1-\lambda}$ is endowed with $(1-\lambda) a_{j}$ and player $j^{\lambda}$ is endowed with $\lambda a_{j}$ (similarly for player $i$ ). By (2) the JV is profitable if

$$
\begin{aligned}
\Delta_{k} v^{C_{0}}\left(S \cup i^{1-\lambda} \cup\left\{i^{\lambda}, j^{\lambda}\right\}\right) & +\Delta_{k} v^{C_{0}}\left(S \cup j^{1-\lambda} \cup\left\{i^{\lambda}, j^{\lambda}\right\}\right)+\Delta_{k} v^{C_{0}}\left(S \cup i^{1-\lambda}\right) \\
& +\Delta_{k} v^{C_{0}}\left(S \cup j^{1-\lambda}\right)-2 \Delta_{k} v^{C_{0}}(S \cup i)-2 \Delta_{k} v^{C_{0}}(S \cup j)<0
\end{aligned}
$$

Adding the zero sum term

$$
-\Delta_{k} v^{C_{0}}\left(S \cup i^{1-\lambda}\right)+\Delta_{k} v^{C_{0}}\left(S \cup i^{1-\lambda}\right)-\Delta_{k} v^{C_{0}}\left(S \cup j^{1-\lambda}\right)+\Delta_{k} v^{C_{0}}\left(S \cup j^{1-\lambda}\right)
$$

Inequality (11) implies

$$
\Delta_{k i \lambda} v^{C_{0}}\left(S \cup i^{1-\lambda}\right)+\Delta_{k j^{\lambda}} v^{C_{0}}\left(S \cup j^{1-\lambda}\right)>\Delta_{k\left\{i^{\lambda}, j^{\lambda}\right\}} v^{C_{0}}\left(S \cup i^{1-\lambda}\right)+\Delta_{k\left\{i^{\lambda}, j^{\lambda}\right\}} v^{C_{0}}\left(S \cup j^{1-\lambda}\right)
$$

for all $k \in N \backslash i \backslash j$ and $S \subseteq N \backslash i \backslash j \backslash k$.

This proposition suggests that if the conferred resources are optimally chosen, the JV may lead to consistent increases in the market power of parent firms.

\section{A measure of asset complementarity}

Measuring complementarity/substitutability implies assessing how industries and firms are related 10 This is notably quite a difficult task. Many existing complementarity measures use industry codes, which provide only qualitative assessments. These measures are commonly used to investigate the correlation between firms' sectors and the occurrence of integration contracts (Gort, 1962; Hassid, 1975; Berry, 1974, Jacquemin and Berry, 1979).

\footnotetext{
${ }^{10}$ Note that substitutability occurs when complementarity is negative.
} 
More sophisticated measures are based on concentric indexes (Caves et al., 1980 and Wernerfelt and Montgomery, 1988) and entropy indexes (Palepu, 1985). They have been used to study diversification (e.g., Morck et al., 1990; Berger and Ofek, 1995), often in connection with accounting data that are available by segment.

The above mentioned measures are of little use for our purpose, the reason being that they are mainly based on the similarity in industry codes and therefore they are sometimes ineffective in identifying complementarities among firms. Take for instance three-digit sectors 311 and 325. They are classified as "unrelated". However, complementarity may still occur at six-digit level. This is the case of oils-refining (NAICS 2007 6-digit code: 311225) and petrochemical (6-digit code: 325110).

To address this kind of issues, we propose an alternative measure of complementarity based on the inter-industry commodity flows.

\subsection{Complementarity index for two multi-industry firms}

More recently, Fan and Lang (2000) proposed a quantitative complementarity index based on Input-Output (I-O) tables. Their complementarity measure between two industries $l$ and $m$, at time $t$, is an average of the degree of correlation between their input and output flows from/to other industries:

$$
\operatorname{COMP} P^{t}(l, m)=\frac{\operatorname{corr}\left(r_{b l}^{t}, r_{b m}^{t}\right)+\operatorname{corr}\left(c_{b l}^{t}, c_{b m}^{t}\right)}{2}
$$

where $r_{b l}^{t}$ and $r_{b m}^{t}$ are the percentages of sector $b$ 's output required to produce one dollar of output in industries $l$ and $m$ respectively, and $c_{b l}^{t}$ and $c_{b m}^{t}$ are the percentages of $l$ and $m$ 's output used by $b$ (with $b \neq l, m)$.

Index (13) is quite appealing. However, it measures the complementarity between pairs of firms belonging to one industry only. In fact, a large majority of firms in our sample produces a variety of goods and/or services belonging to different industries. Each of them is characterized by a specific level of complementarity with other industries. For this reason, 
we start from the work of Fan and Lang and we build a measure of complementarity which accounts for the possibility that firms operate in more than one industry.

Consider two firms $i$ and $j$ in our sample. The $i$ and $j$ 's products are included in a number of industries: $l=1, \ldots, L$ and $m=1, \ldots, M$, respectively. Let $i_{l}$ be the output of firm $i$ in sector $l$ and $j_{m}$ the output of firm $j$ in sector $m$. In a given year $t$, our complementarity index between multi-industry firms $i$ and $j$ is:

$$
C O M P_{i, j}^{t}=\frac{1}{L \cdot M} \sum_{l=1}^{L} \sum_{m=1}^{M} R_{j}^{t} \cdot \operatorname{COMP}^{t}\left(i_{l}, j_{m}\right)
$$

where $C O M P^{t}\left(i_{l}, j_{m}\right)$ is built using (13). Roughly speaking, (14) "translates" the complementarity between two sectors into complementarity between two firms. Complementarity between two firms is high if they sell their products to (or buy their inputs from) other firms in highly complementary sectors. Moreover, if the two firms do business in several sectors, their degree of complementarity is a weighted average of the complementarity among those sectors.

Index (14) detects variations in complementarity resulting from technological changes, or firms' strategic choices (e.g., the launch of a new product or the desertion of an old one). The value of $R_{j}^{t}$ represents $j$ 's share of the two partners' total operating revenue turnover in year $t$. It gives an idea of contribution that firm $j$ makes to the joint activities with $i$. Notice that $C O M P_{i, j}^{t}$ can also be negative. In this case firms $i$ and $j$ are substitutable.

Let us now explain in what respect index $C O M P_{i, j}^{t}$ is related to the second-order difference operator $\Delta_{i j}^{2} v^{C}(S)$ that we use in the profitability conditions of propositions 1-4 in section 2. By Ichiishi (1993), complementarity between $i$ and $j$ is given by the change in $i$ 's marginal contribution to the value of a coalition. The change is due to the presence of $j$. Formally, $\Delta_{i j}^{2} v^{C}(S)=\Delta_{i} v^{C}(S \cup j)-\Delta_{i} v^{C}(S)$. The higher the value $i$ can add to a set $S$ of firms when also $j$ does business with those firms, the higher $i$ 's complementarity with $j$. In this case we expect $i$ 's business to be positively correlated with $j$ 's business. In other 
words, since $i$ 's contribution is positively affected by the presence of $j$, then $i$ is more likely to sell output to (or to buy inputs from) firms in certain sectors when also $j$ does business with firms in those sectors. Vice versa, if $i$ and $j$ are substitute, we expect $i$ 's business to be negatively correlated with $j$ 's business.

Given a set of firms $S$ with which $i$ and $j$ do business, the higher the correlation between $i$ 's and $j$ 's inter-industry relationships with members of $S$, as measured by terms $C O M P^{t}\left(i_{l}, j_{m}\right)$ in formula (14), the higher $\Delta_{i j}^{2} v^{C}(S)$. This explains how correlations in the input-output tables are related to variations in the characteristic function, $v^{C}$. Ultimately, it explains why $\Delta_{i j}^{2} v^{C}(S)$ and $C O M P^{t}\left(i_{l}, j_{m}\right)$ should be positively related.

Now observe that $\Delta_{i j}^{2} v^{C}(S)$ depends on $S$. In fact, propositions 1-4 present profitability conditions that hinge on variations of $\Delta_{i j}^{2} v^{C}(S)$. Those conditions must hold for all coalitions $S$. If this is the case, they hold also for the sum of $\Delta_{i j}^{2} v^{C}(S)$ over all $S$. By 14 , our complementarity index $C O M P_{i, j}^{t}$ represents a weighted sum of complementarity indexes $C O M P^{t}\left(i_{l}, j_{m}\right)$ over all $i$ and $j$ 's activities based on the sectors where they sell their products or buy their inputs. Thus, $C O M P_{i, j}^{t}$ represents a proxy of the sum of $\Delta_{i j}^{2} v^{C}(S)$ over all coalitions $S$. We provide further details on this point while discussing the empirical strategy in subsection 5.1 .

For a better understanding of how index $C O M P_{i, j}^{t}$ works and how it maps to the model in section 2, consider the following example. In 2007 the Curtiss-Wright Corporation, a company which has a long tradition in the design, development and manufacture of innovative and advanced technologies for commercial, industrial, defense and energy markets, acquired the stock of Benshaw Advanced Controls \& Drives for approximately $\$ 102$ million. Benshaw operates in the design, development and manufacture of mission critical motor control and protection product solutions for leading original equipment manufacturers (OEMs) and industrial customers.

The primary NAICS 2007 codes for Curtiss-Wright are: 332812 (Metal Coating, Engraving and Allied Services to Manufacturers); 334413 (Semiconductor and Related Device 
Manufacturing) and 33641 (Aerospace Product and Parts Manufacturing). For Benshaw: 3345 (Navigational, Measuring, Electromedical, and Control Instruments Manufacturing).

Curtiss-Wright is the acquiror $i$ (with a number $L=3$ of activities) while Benshaw is the target $j$ (with $M=1$ activities). Since the I-O Tables refer to the 3-digit codes of 2007 classification, we define sectors as follows: $i_{1}=332, i_{2}=334, i_{3}=336$ and $j_{1}=334$.

We use formula (13) to compute index $\operatorname{COMP}^{t}(l, m)$ between each sector $l$ of $i$ and each sector $m$ of $j$, for years $t=2006,2007$ (see results in table 1). Consider the first year 2006. The operating revenue turnover amounts to $\$ 939$ million for Curtiss-Wright and $\$ 52$ million for Bensham, implying that the Bensham's contribution to the total operating revenue is about $5.5 \%$, therefore $R_{j}^{2006}=0.05$. By $(14)$, the complementarity index between Curtiss-Wright and Bensham ( $i$ and $j$, respectively) is

$$
\begin{array}{r}
C O M P_{i, j}^{2006}=\frac{1}{L \cdot M} \cdot R_{j}^{2006} \cdot\left[C O M P^{2006}\left(i_{1}, j_{1}\right)+C O M P^{2006}\left(i_{2}, j_{1}\right)+C O M P^{2006}\left(i_{3}, j_{1}\right)\right]= \\
\frac{0.05}{3} \cdot(0.2073+1.0000+0.1660)=0.0251
\end{array}
$$

In the same way, we also compute the value for year 2007. Table 1 shows all results.

Table 1: Complementarity index between Curtiss-Wright and Benshaw's in period

\begin{tabular}{|c|c|c|c|}
\hline \multicolumn{2}{|c|}{ Year 2006} & \multicolumn{2}{|c|}{ Year 2007} \\
\hline$C O M P^{2006}\left(i_{1}, j_{1}\right)$ & 0.2073 & $C O M P^{2007}\left(i_{1}, j_{1}\right)$ & 0.2162 \\
\hline$C O M P^{2006}\left(i_{2}, j_{1}\right)$ & 1.0000 & $C O M P^{2007}\left(i_{2}, j_{1}\right)$ & 1.0000 \\
\hline$C O M P^{2006}\left(i_{3}, j_{1}\right)$ & 0.1660 & $C O M P^{2007}\left(i_{3}, j_{1}\right)$ & 0.1547 \\
\hline$R_{j}^{2006}$ & 0.0550 & $R_{j}^{2007}$ & 0.0600 \\
\hline$C O M P_{i, j}^{20}$ & 0.0251 & $C O M P_{i, j}^{2007}$ & 0.0274 \\
\hline
\end{tabular}
2006-2007.

The complementarity index between Curtiss-Wright and Bensham is quite low in the two years: only 0.0251 in 2006 and 0.0274 in 2007 . The reason is twofold.

First, values $C O M P^{t}\left(i_{l}, j_{m}\right)$ in the weighted sum of index (14) are rather low: always below 0.22 , except for sector 334 , which is the sector where the two partners almost perfectly 
overlap either in terms of inputs required or in terms of markets to which they sell their products. As a consequence, should an integration contract between the two companies occur, synergies and business opportunities between the two companies appear to be modest.

Second, Bensham's share $R_{j}^{t}$ of total operating revenue turnover is very low (never above $6 \%$ ). It implies that, in the case of integration, the contribution of Bensham to CurtissWright's business is expected to be relatively small.

\subsection{Complementarity in the presence of third parties}

The model of section 2 points out that benefits from an integration contract are due not only to complementarity between $i$ and $j$, but also to possible changes in complementarity/substitutability between them and any third party, $k$. To evaluate empirically the strategic effects of integration, we build complementarity indexes based on a weighted average of $i$ 's (or $j$ 's) complementarity indexes with any third party $k$. The complementarity between $i$ and third parties $k \mathrm{~s}$ (in year $t$ ) is

$$
C k i^{t}=\sum_{K} R_{k}^{t} C O M P_{k, i}^{t}
$$

The weights $R_{k}^{t}$ account for the relative importance of third parties in our sample. Specifically, $R_{k}^{t}$ is the share of the total operating revenue turnover of $k$, and $K$ is the set of all third parties $k \neq i, j$. Index $C k i^{t}$ is a proxy for the average of the difference operator $\Delta_{k i}^{2} v^{C}(S)$. Similarly, we also define $C k j^{t}$, proxy for the average of $\Delta_{k j}^{2} v^{C}(S){ }^{11}$ Using indexes $C O M P_{k, i}^{t}$, $C O M P_{k, j}^{t}$ and $C O M P_{i, j}^{t}$, we build index $C k i j^{t}$, that represents the complementarity between partners, taken together, and third parties:

$$
C k i j^{t}=\sum_{K} R_{k}^{t} C O M P_{k, i}^{t} \cdot C O M P_{i, j}^{t}+\sum_{K} R_{k}^{t} C O M P_{k, j}^{t} \cdot C O M P_{i, j}^{t}
$$

\footnotetext{
${ }^{11}$ Specifically,$$
C k j^{t}=\sum_{K} R_{k}^{t} C O M P_{k, j}^{t}
$$ 
Index $C k i j^{t}$ is a proxy for the average of $\Delta_{k\{i, j\}}^{2} v^{C}(S)$, the post-integration complementarity, and it will be required to test condition (5) for M\&A contracts.

Following the same steps, we define complementarity indexes needed to test profitability conditions for MS and JV contracts. For example, suppose $i$ acquires a minority share $\lambda$ of $j$ 's resources. A proxy for the average of $\Delta_{k j^{\lambda}}^{2} v^{C}\left(S \cup j^{1-\lambda}\right)$ in $(8)$ is:

$$
C k j^{\lambda, t}=\sum_{K \cup j^{1-\lambda}} R_{k}^{t} C O M P_{k j^{\lambda}}^{t}
$$

Observe that in the case of MS or JV, the target firm $j$ controls resources $(1-\lambda) a_{j}$ independently of $i$. In other words, as far as $(1-\lambda) a_{j}$ are concerned, $j$ can be considered a third party from the point of view of the integrating partners. This the reason why index (17) includes $j^{1-\lambda}$ in the set of third parties $K$.

All indexes above belong to the interval $[-1,1]$. They are time varying, because I-O Tables are updated yearly.

\section{The sample and some descriptive statistics}

Data come from databases Orbis and Zephyr (Bureau Van Dijk) and refer to 8106 US listed companies that signed a bilateral contract of M\&A (416 units), MS (6495) or JV (1195) in the period 2002-2007. Contracts involved companies operating in 90 different primary industrial sectors (NAICS 2007 6-digit classification). ${ }^{12}$ Including the secondary firm activities, the M\&A and MS contracts occurred in 105 different industrial sectors, whereas the JVs were recorded in 58 sectors. Table 2 provides a classification of integration contracts by completion year.

\footnotetext{
${ }^{12}$ In the final Appendix we provide the sample characteristics of top four business sectors for each of the three contracts (see table 9).
} 
Table 2: Sample decomposition by year of integration.

\begin{tabular}{lccccccc}
\hline & \multicolumn{7}{c}{ Year } \\
\cline { 2 - 7 } & 2002 & 2003 & 2004 & 2005 & 2006 & 2007 & Total \\
\hline M\&A & 24 & 43 & 49 & 118 & 99 & 83 & 416 \\
MS & 519 & 766 & 690 & 1334 & 2887 & 299 & 6495 \\
JV & 120 & 167 & 245 & 199 & 207 & 257 & 1195 \\
\hline Total & 663 & 976 & 984 & 1651 & 3193 & 639 & 8106 \\
\hline
\end{tabular}

The largest number of deals have been completed in year 2005 in the case of M\&A (118 out of 416), in 2006 for MS purchases (2887/6495) and 2007 for JVs (257/1195). All together, the contracts signed in this period 2005-2007 cover the $40.2 \%$ of the sample.

Descriptive statistics on size, deal value and performance are reported in Table 3. Data concern firms between the 25th and 75th percentile of the distribution, in the year before integration ${ }^{13}$ The variables we used as proxies for size (i.e., number of employees, enterprise value, total assets, sales) confirm that on average firms engaging in an M\&A are smaller than in case of MS or JV. For instance, the 75th percentile for the number of employees is only 750 for M\&As, whereas this value rises to more than 28000 for MS and to 41200 for JV contracts. Not surprisingly, this ranking in size also reflects the average value of deals by contract (notice that the 75 th percentile for JVs is in this case almost eight times the value for M\&As, while that for MS purchases is more than double).

Firms choosing M\&A integration are also the least performing: the $75 \%$ of them show an annual ROA (return on assets) not higher than 1.50\%, compared to a value of $7.34 \%$ for MS purchases and $6.50 \%$ for JVs. This scenario does not change when performance is measured by using ROSF (return on shareholders funds) or EBIT (earnings before interest and taxes).

\footnotetext{
${ }^{13}$ The final Appendix provides definitions of all reported data.
} 
Table 3: Summary Statistics: Interquartile ranges of data related to the pre-integration

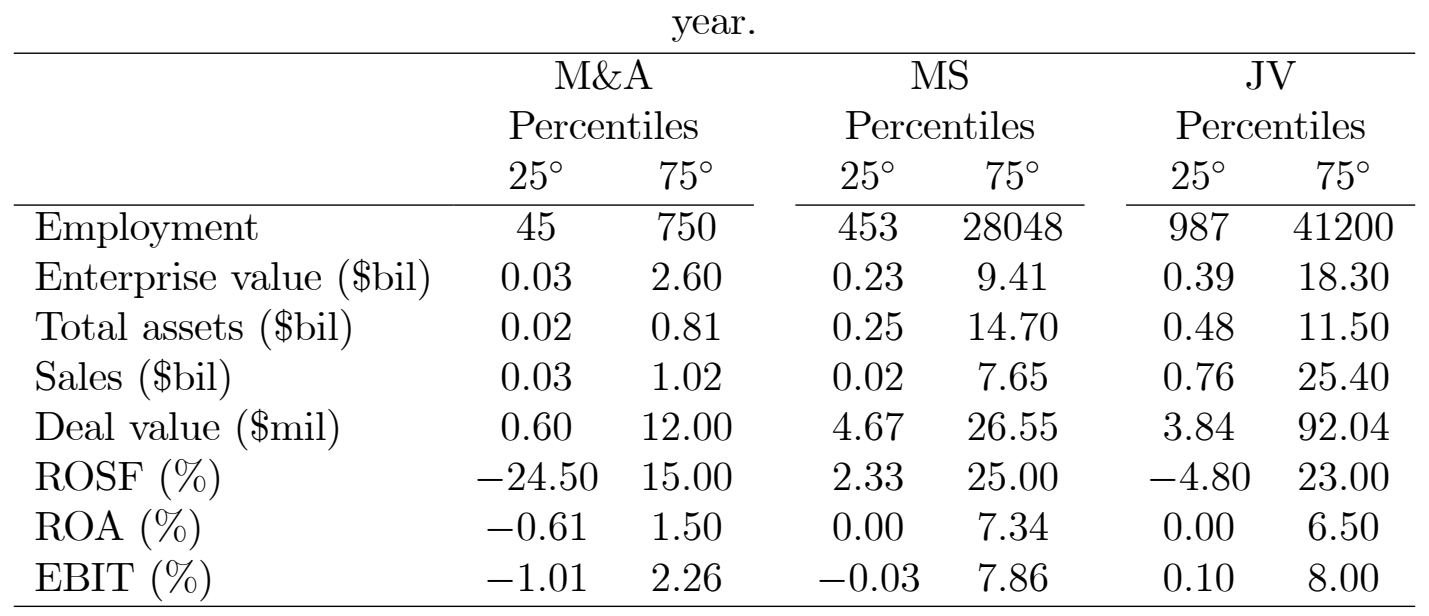

Table 4 shows that firms signing an M\&A contract look for partners with a higher degree of complementarity. These data are consistent with our conjecture that firms involved in MSs or JVs are relatively less motivated by the chance to benefit from positive productivity effects and relatively more attracted by potential strategic effects on third parties.

Table 4: Complementarity index between partners. Descriptive statistics by integration

\begin{tabular}{ccccc}
\multicolumn{5}{c}{ contract $(t=$ pre-integration year $)}$. \\
\hline \multicolumn{5}{c}{ M\&A } \\
COMP $P_{i, j}^{t}$ & 0.0013 & Std. Dev. & Min & Max \\
& Mean & Std. Dev. & Min & Max \\
COMP $P_{i, j}^{t}$ & 0.0002 & 0.0066 & -0.0351 & 0.4116 \\
\hline \multicolumn{5}{c}{ JV } \\
$C O M P_{i, j}^{t}$ & Mean & Std. Dev. & Min & Max \\
& 0.0005 & 0.0081 & -0.0412 & 0.1600 \\
\hline
\end{tabular}

Further support to our conjecture comes from table 5. It presents the correlation of partners' complementarity index, $C O M P_{i, j}^{t}$, with both the size and the performance of integrating firms. As far as an M\&A is concerned, correlation is significantly negative. Instead, the correlation is weakly positive for minority stakes contracts, while it is or not significant for JVs. 
Table 5: Correlation of partners' complementarity index with firm size and performance $(t$

\begin{tabular}{|c|c|c|c|}
\hline$C O M P_{i, j}^{t}$ & $\mathrm{M} \& \mathrm{~A}$ & MS & JV \\
\hline Employees & $-0.34^{*}$ & $0.63^{*}$ & 0.00 \\
\hline Total assets & $-0.10^{*}$ & $0.03^{*}$ & 0.05 \\
\hline $\mathrm{ROA}$ & $-0.12^{*}$ & $0.08^{*}$ & 0.05 \\
\hline ROSF & $-0.30^{*}$ & $0.19^{*}$ & $0.15^{*}$ \\
\hline
\end{tabular}

* Significant at $5 \%(p<0.05)$.

\section{Empirical evidence}

\subsection{Strategy}

We use panel data to test if the profitability conditions derived in section 2 are significantly and positively correlated with firms' performance, in case of integration. Specifically, we want to test whether and how performance is related to changes in partners' complementarity with third parties.

Profitability conditions hinge on variations in second-order differences of the characteristic function, due to change in the control structure. As pointed out in subsection 3.1, the time varying idiosyncratic terms in the empirical model are intended to capture those factors that shape the characteristic function $v^{C}(S)$ in the theoretical model, and ultimately the degree of complementarity/substitutability between members of $S$. This is how the empirical analysis maps to the theoretical model (cf. further discussion on this point below).

Using the Input-Output Accounts Data available from the U.S. Bureau of Economic Analysis (BEA), we measure complementarity/substitutability relationships defined in section $3{ }^{14}$ For each company, we take into account up to 8 different business lines ranked by relevance in terms of revenues.

We compare the performance of our sample to that of a "control" group including 33212 non-integrating companies. For each contract, this set of firms is used as a counterfactual

\footnotetext{
${ }^{14}$ It is worth mentioning that when complementarity indexes are negative (e.g., index 14 (15) or 15 ), then firms are substitutable. In this case, by lower complementarity we mean higher substitutability.
} 
to evaluate the relative performance of integrating firms, which we call "treated". Similarity between control and treated units is based on estimated treatment probabilities, known as propensity scores (see Rosenbaum and Rubin, 1983). Propensity score matching is implemented by using a logit on a vector $\mathbf{X}$ of firm pre-treatment characteristics.

In this vector we include proxy variables for $i$ ) size (number of employees, sales, fixed and total assets, operating revenue turnover, enterprise value); ii) quality of company's income (cash flow); iii) profitability (EBIT, gross profit, value added, ROSF), and finally a sectoral dummy variable that takes into account the companies' industrial activities. Once we have checked that the balancing property is satisfied ${ }^{15}$, we estimate the joint impact of integration contracts and profitability conditions on the firm performance.

This matching procedure addresses a self-selection problem concerning the choice of the contract. We assume that firms do not choose their contracts based on some known changes in complementarities or some firm characteristics. Accordingly, we do not run regressions designed to test the decision of signing a specific contract conditional to our profitability conditions (5), (8) and (12). Rather, we test whether these conditions are really effective, which implies assessing their impact on the partners' performance once the contract has been chosen. Thus we use propensity score matching to randomize the choice of contracts in our sample and finally test the impact of profitability conditions.

The dependent variable in the empirical model is $R O A$ (return on assets), the ratio between a company's annual earnings and its total assets. As contracts have important implications on some characteristics of the firms (e.g., size, efficiency, productivity), we use a dynamic model for panel data which takes into account autocorrelation in the variable measuring firm performance. We adopt the dynamic GMM proposed by Blundell and Bond (1998), where variables are instrumented by using their lagged and non-lagged firstdifferences ${ }^{16}$ For each company $i$ we set a time varying dummy $T_{i t}$ taking value of 1 from

\footnotetext{
${ }^{15}$ The balancing property requires that treated and controls have on average the same characteristics.

${ }^{16}$ For predetermined and endogenous variables, two is the maximum number of lags used as instruments.
} 
the generic year $t$ in which integration occurs. This variable takes always value 0 for nonintegrated firms belonging to counterfactual group.

The model is:

$$
R O A_{i t}=\alpha R O A_{i t-1}+\delta_{\mathbf{1}} \mathbf{S I Z E}_{i t}+\delta_{2} T_{i t} \times P C_{i t}+\delta_{\mathbf{3}} \mathbf{T C}_{i t}+\mu_{i}+y_{t}+\epsilon_{i t}
$$

The row vector $S I Z E_{i t}$ includes variables $S A L E S_{i t}$ (net sales, in natural $\log$ ), $E M P L_{i t}$ (number of employees, in natural log) and their first order lags.

As first step, we use model (18) to test the general profitability requirements from propositions 1, 2 and 4 in section 2, Then, in section 5.3, we implement the ANOVA technique to check whether a MS contract is more profitable than M\&A when condition (10) holds, as suggested by proposition 3 .

To test theoretical predictions we use the interaction term $T_{i t} \times P C_{i t}$, where $P C_{i t}$ is a dummy indicating whether the profitability condition associated with contract $T_{i t}$ is satisfied or not in year $t$. For example, consider an M\&A contract. Inequality (5) is the profitability condition associated with this contract. It says that a sufficient condition for profitability is that the M\&A reduces the partners' complementarity with all third parties in our sample. Using indexes defined in section 3 , this condition implies $C k i j^{t}<C k i^{t}+C k j^{t}$. If this inequality holds, then the dummy variable $P C_{i t}$ takes value 1 for company $i$. Hence, through the interaction term $T_{i t} \times P C_{i t}$ we can evaluate how profitability conditions correlate with post-integration profits.

For each company $i$, and any period $t$, vector $T C_{i t}$ in $(18)$ is composed of interactions of $T_{i t}$ with the following three complementarity indexes. First, $C O M P_{i, j}^{t}$ defined by (14) measures complementarity between $i$ and $j$. It assesses mutual benefits eventually arising from merging partners' assets (the productivity effect), without taking into account any possible effect due to changes in the complementarity with third parties (e.g., the strategic effect). Second, index $C k i^{t}$ measures complementarity between partner $i$ and all third parties, 
$k$. Specifically, for year $t$, the complementarity index $C k i^{t}$ is defined by (15). The third index $C k j^{t}$ is defined in the same way, where $i=j$. All of these three complementarity indexes are time varying ${ }^{17}$ Finally, $\mu$ and $y$ in (18) represent firm and time specific effects; $\epsilon$ is the usual disturbance term.

\subsection{Results}

Columns (1)-(3) in table 6 show results of our regressions for M\&A, MS and JV contracts, respectively. To save notation, hereafter we omit dimension $i$ and $t$ for variables referring to panel data. For each contract, we disentangle the productivity and strategic effect in order to assess their relative importance. The productivity effect is captured by the interaction term $T \times C O M P_{i, j}$, while the strategic effect operates through the three interactions of variable $T$ with dummy variable $P C$ and the complementarity indexes $C k i, C k j$.

We find evidence that post-integration profits are higher when our theoretical profitability conditions are satisfied. The variable of interest is $T \times P C$, the interaction between the two dummies for treatment and profitability conditions. Profits increase on average by $1.51 \%$ and $2.18 \%$ for MS and JV, respectively (cf. table 6. Columns 2 and 3). These percentages are higher than the average $1.45 \%$ for an M\&A.

Coefficients for treatment variable $T$ are significantly negative in all cases, especially for JVs, where the average loss is about $2 \%$. This result suggests that integration contracts do not yield higher profits per se. If instead profitability conditions are satisfied, integration contracts are associated with higher profits. The interaction term $T \times P C$ is a first channel to capture the strategic effect of integration contracts empirically. Additional strategic gains come from changes in the complementarity/substitutability between each partner and third parties. The impact is measured by interactions $T \times C k i$ and $T \times C k j$. Cumulating the impacts of these channels, we can evaluate the relative strength of strategic and productivity effects for each contract.

\footnotetext{
${ }^{17}$ We do not include in our regressions the complementarity index $C k i j^{t}$, defined by $(16)$, because it is a linear combination of $C k i^{t}, C k j^{t}$ and $C O M P_{i, j}^{t}$, so giving rise to a multicollinearity problem.
} 
In an M\&A profits increase on average by $4.50 \%$ for every increase of the complementarity between the acquiror $i$ and third parties, as measured by $T \times C k i$, and by $0.37 \%$ for every decrease of complementarity between the target and third parties $(T \times C k j)$. The "productivity effect" is the effect of partners' complementarity, as measured by $T \times C O M P_{i, j}$. For M\&A contracts, the average effect is strongly negative $(-4.33 \%)$. These results suggest that the perspective of gaining from the strategic effects produced by the integration represents a strong motivation to sign an M\&A contract. This motivation may be stronger than the prospect of achieving productivity gains.

In the case of MS contracts the largest impact from strategic effect is related to the substitutability between target $j$ and third parties, as measured by the coefficient value of $T \times C k j$. A decrease in their complementarity index (or alternatively, any increase in substitutability) is associated with a $4.58 \%$ increase in profits, on average. These gains are on top of those coming from profitability condition $P C(+1.51 \%)$. They outweigh the productivity effect, which is negative also for this type of contract. The value of coefficient for variable $T \times C O M P_{i, j}$ is -4.71 . Thus, as for M\&As, also for MS contracts a substantial increase in profits is associated with the strategic effects on competitors and trading parties.

In the case of a $\mathrm{JV}$, any increase in $C k j$ guarantees additional returns of 3.51 percentage points (see Column 3 in table 6). Eventually, these gains can be added to those from the profitability condition (2.18 percentage points). Differently from the other two contracts, complementarity between partners has a positive effect on post-integration performance. The coefficient value for $T \times C O M P_{i, j}$ is +2.50 . Thus the productivity effect is positive. However, as for the other two contracts, the strategic effect appears to be a strong motivation of the choice of forming a JV. 
Table 6: Complementarity and post-integration performance.

Dynamic GMM (Blundell-Bond, 1998) estimators.

\begin{tabular}{|c|c|c|c|}
\hline & (1) & $(2)$ & $(3)$ \\
\hline Dep. $R O A$ & $\mathrm{M} \& \mathrm{~A}$ & MS & JV \\
\hline \multirow[t]{2}{*}{$R O A(t-1)$} & $0.0939^{* * *}$ & $0.2000^{* * *}$ & $0.1602^{* * *}$ \\
\hline & $(0.0010)$ & $(0.0078)$ & $(0.0047)$ \\
\hline \multirow[t]{2}{*}{$S A L E S$} & $0.0005^{* * *}$ & $0.0000^{* * *}$ & $0.0000^{* * *}$ \\
\hline & $(0.0000)$ & $(0.0000)$ & $(0.0000)$ \\
\hline \multirow[t]{2}{*}{$S A L E S(t-1)$} & $-0.0001^{* * *}$ & $-0.0000^{* * *}$ & $-0.0000^{* * *}$ \\
\hline & $(0.0000)$ & $(0.0000)$ & $(0.0000)$ \\
\hline \multirow[t]{2}{*}{$E M P L$} & $-0.2067^{* * *}$ & $-0.0000^{* *}$ & $-0.0002^{* * *}$ \\
\hline & $(0.0041)$ & $(0.0000)$ & $(0.0000)$ \\
\hline \multirow[t]{2}{*}{$E M P L(t-1)$} & $-0.0447^{* * *}$ & $0.0001^{* * *}$ & $0.0001^{* * *}$ \\
\hline & $(0.0031)$ & $(0.0000)$ & $(0.0000)$ \\
\hline \multirow[t]{2}{*}{$T$} & $-1.6415^{* * *}$ & $-0.6963^{* *}$ & $-2.0651^{* * *}$ \\
\hline & $(0.0949)$ & $(0.2888)$ & $(0.2498)$ \\
\hline \multirow[t]{2}{*}{$P C$} & $-0.1271^{* * *}$ & -0.2384 & $0.4500^{* * *}$ \\
\hline & $(0.0369)$ & $(0.1770)$ & $(0.1058)$ \\
\hline \multirow[t]{2}{*}{$T \times P C$} & $1.4537^{* * *}$ & $1.5132^{* * *}$ & $2.1796^{* *}$ \\
\hline & $(0.1928)$ & $(0.4459)$ & $(0.2696)$ \\
\hline \multirow[t]{2}{*}{$T \times C O M P_{i, j}$} & $-4.3349^{* *}$ & $-4.7086^{* * *}$ & $2.5050^{* * *}$ \\
\hline & $(2.3387)$ & $(0.7641)$ & $(0.1623)$ \\
\hline \multirow[t]{2}{*}{$T \times C k i$} & $4.4917^{* * *}$ & -1.8978 & 1.4446 \\
\hline & $(0.4644)$ & $(1.3058)$ & $(1.0128)$ \\
\hline \multirow[t]{2}{*}{$T \times C k j$} & $-0.3668^{* * *}$ & $-4.5773^{* * *}$ & $3.5149^{* * *}$ \\
\hline & $(0.0650)$ & $(1.6669)$ & $(1.1796)$ \\
\hline \multirow[t]{2}{*}{ Const. } & $1.1607^{* * *}$ & $0.6952^{* * *}$ & $1.5070^{* * *}$ \\
\hline & $(0.0675)$ & $(0.2244)$ & $(0.4274)$ \\
\hline$N$ & 1635 & 32262 & 6910 \\
\hline
\end{tabular}

Notes. Standard errors in parentheses; ${ }^{* * *} p<0.01,{ }^{* *} p<0.05,{ }^{*} p<0.1$.

Data for complementarity indexes are $\times 100$. All regressions include firm and time fixed effects. 


\subsection{Average effect of profitability conditions}

Within the sample of firms that signed an integration contract in the period 2002-2007 we distinguish between treated and controls. A "treated" firm satisfies the profitability requirement associated with its contract, therefore the treatment group includes all firms such that the dummy variable $P C$ takes value 1 starting from the year of integration. The "control" group includes firms that do not satisfy their profitability conditions, that is all units such that the dummy variable $P C$ takes value 0 .

Thus we explore the impact of profitability conditions once firms have chosen their contract. Basically, our analysis involves two counterfactuals for a single set of integrated firms. The first counterfactual is related to the choice of a specific integration contract than another. The second is related to changes in complementarity relationships but conditioning on the contract that firms have chosen. In order to ensure similarity between treated and controls, we implement the same propensity score matching presented in section 5. Namely, we use a logit on a vector of twelve pre-treatment variables that summarize the main features of firms in our sample.

Then we estimate the Average Treatment Effect $(A T E)$, which requires finding matches for both the treated and the control units, and the Average Treatment Effect on the Treated $(A T E T)$, which in turn only requires finding matches for the treated. The post-integration period includes three years after the contract completion date and performance is measured by using ROA (return on assets). Results in table 7 support theoretical predictions. When profitability conditions are satisfied, a significant increase in the rate of return occurs. The $A T E$ is about +1.73 percentage points in the first post-integration year, and even higher $(+1.87 \%)$ in the second year. This boost effect disappears in the third year. Over all three years, the returns after integration grow by $+1.30 \%$ a year, at $1 \%$ level of significance.

When matching treated and control only on the treated (ATET), results are quite similar. The impact is slightly lower in the first post-integration year, $+1.60 \%$, but higher in the second year, where the profitability conditions guarantee an extra gain of $+2.20 \%$. On 
average, returns grow by $+1.20 \%$ a year.

Finally, we test whether a MS is associated with a larger increase in profits compared to an M\&A, provided that the MS contract significantly reduces the complementarity between acquiror and third parties (i.e., condition 100 holds). For this purpose, we consider a subsample of firms that satisfy both the profitability conditions (5) and (10) in the year of integration. For these firms, both M\&As and MSs are associated with an increase in profits. Then we use the analysis of variance (ANOVA) to compare the average performance of firms choosing the two different contracts. Table 8 shows the results. The one-way ANOVA highlights a boost effect from MS contracts. The probability ( $p$-value) associated with the differences between groups is less than 0.01 (see Sig. level in table 8). Therefore differences between the two contracts are valid and statistically significant at $1 \%$. When firms choose a MS contract the average ROA is higher: 3.63 percentage points more than an M\&A. Interestingly, this boost effect still amounts to $2.62 \%$ for firms choosing a JV contract.

Table 7: Average Treatment Effect (ATE) and Average Treatment Effect on Treated (ATET) from integration Profitability Conditions.

\begin{tabular}{lcccc}
\hline Dep. ROA & \multicolumn{4}{c}{ ATE } \\
\hline Post-integration years: & $A l l$ & $t+1$ & $t+2$ & $t+3$ \\
\cline { 2 - 5 } & $1.280^{* * *}$ & $1.728^{* *}$ & $1.868^{* *}$ & 0.204 \\
& $(0.000)$ & $(0.013)$ & $(0.023)$ & $(0.733)$ \\
\cline { 2 - 5 } & \multicolumn{4}{c}{ ATET } \\
\cline { 2 - 5 } & $1.162^{* * *}$ & $1.557^{* *}$ & $2.197^{* *}$ & -0.150 \\
& $(0.002)$ & $(0.040)$ & $(0.019)$ & $(0.808)$ \\
\hline$N$ & 9022 & 2266 & 2248 & 2253 \\
\hline
\end{tabular}

Notes. Treated: $P C=1$; Controls: $P C=0$.

${ }^{* * *} p<0.01,{ }^{* *} p<0.05,{ }^{*} p<0.1 ; p$-values in parentheses. 
Table 8: ANOVA for post-integration performance.

\begin{tabular}{cccccc} 
& Sum of squares & df & Mean square & F & Sig. \\
\hline Between groups & 10396.0441 & 2 & 5198.0220 & 36.76 & 0.0000 \\
Within groups & 2466364.22 & 17441 & 141.41186 & & \\
\hline Pairwise comparisons of the means (Bonferroni's method): & & \\
M\&A & 0 (base) & & \\
MS & $+3.630^{* * *}$ \\
JV & $+2.618^{* * *}$ & & \\
\hline
\end{tabular}

Notes. Treatment variable includes three categories: M\&A, MS and JV.

The subsample includes firms that satisfy profitability conditions $\quad 5$ and 10 for M\&A and MS.

Standard errors in parentheses; ${ }^{* * *} p<0.01,{ }^{* *} p<0.05,{ }^{*} p<0.1$. 


\section{Conclusions}

In this paper we adopt the approach of cooperative game theory to study integration contracts. We build on the seminal work of Segal (2003) by extending it in two directions. First, we consider integration contracts that pool less than $100 \%$ of partner's resources. Second, we provide empirical evidence of theoretical predictions.

In the model, integration may yield two effects. First, it may enhance efficiency, due to complementarity between partners' resources (i.e., the productivity effect). Second, it may increase partners' market power, by making competitors' and other parties' resources less essential (i.e., the strategic effect). A minority stakeholding or a JV can be more profitable than an M\&A. The reason is that pooling less than 100\% resources may yield a larger strategic effect, compared to full integration. It can allow partners to decrease third parties' complementarity (or increase their substitutability) by a larger amount. Third parties' contributions become less valuable than in the case of an M\&A. Thus integrating partners gain more market power and higher profits.

In order to provide empirical evidence, we use a large sample of US quoted companies. We develop an index based on the I-O coefficients to measure complementarity/substitutability among firms. This index is time varying and applies to multi-product firms.

We find that profits are higher when theoretical profitability conditions are satisfied. The productivity effect is negative for M\&A and MS contracts, while it is positive for JVs. The strategic effect is positive, and it is relatively more important for partial integration contracts than for M\&As. These results support our conjecture that the strategic effect may yield consistent increase in profits, even in the presence of limited efficiency gains. Moreover,

minority stakes contracts and JVs are likely to lead to larger accumulation of market power, compared to M\&As.

From a normative viewpoint, our results on strategic implications of MS and JV con- 
tracts imply that the acquisition of non-controlling minority shareholding (and the strategic alliances as well) are more likely to harm competition and then consumers, compared to M\&A contracts. However, antitrust legislation is quite heterogeneous across countries on this issue. In some countries (e.g., the US, Japan, UK or Germany), the Competition Authorities are given the competence to review any kind of minority acquisitions. In other jurisdictions (e.g., the European Commission or some EU members), the authorities cannot investigate minority shareholdings which do not lead to the acquisition of full control.

There is not much consensus about the potential harms of minority shareholding. Perhaps the theoretical framework and the empirical findings of this paper help shed light on these important normative issues.

\section{References}

Berger, P. G., Ofek, E., 1995. Diversification's effect on firm value. Journal of Financial Economics 37 (1), 39-65.

Berry, C. H., 1974. Corporate diversification and market structure. Bell Journal of Economics $5(1), 196-204$.

Bethel, J. E., Hu, G., Wang, Q., 2009. The market for shareholder voting rights around mergers and acquisitions: Evidence from institutional daily trading and voting. Journal of Corporate Finance 15 (1), 129-145.

Bhagat, S., Brickley, J. A., 1984. Cumulative voting: The value of minority shareholder voting rights. Journal of Law and Economics 27 (2), 339-65.

Blundell, R., Bond, S., 1998. Initial conditions and moment restrictions in dynamic panel data models. Journal of Econometrics 87 (1), 115-143.

Bodnaruk, A., Massa, M., Simonov, A., 2013. Alliances and corporate governance. Journal of Financial Economics 107 (3), 671-693. 
Butz, D. A., 1994. How do large minority shareholders wield control? Managerial and Decision Economics 15 (4), 291-298.

Caves, R. E., Porter, M. A., Spence, A. M., 1980. Competition in the Open Economy. Cambridge, Mass.: Harvard University Press.

Chipty, T., Snyder, C., 1999. The role of firm size in bilateral bargaining: A study of the cable television industry. The Review of Economics and Statistics 81 (2), 326-340.

Ciccotello, C. S., Hornyak, M. J., 2000. Cooperation via contract: An analysis of research and development agreements. Journal of Corporate Finance 6 (1), 1-24.

Davidson, C., 1988. Multiunit bargaining in oligopolistic industries. Journal of Labor Economics 6 (3), 397-422.

Elfenbein, D. W., Lerner, J., 2012. Exclusivity, contingent control rights, and the design of internet portal alliances. Journal of Law, Economics and Organization 28 (1), 45-76.

Elliott, M., 2015. Inefficiencies in networked markets. American Economic Journal: Microeconomics 7 (4), 43-82.

Fan, J. P., Lang, L. H., 2000. The measurement of relatedness: An application to corporate diversification. Journal of Business 73 (4), 629-660.

Gort, M., 1962. Introduction to "Diversification and integration in American industry". In: Diversification and Integration in American Industry. National Bureau of Economic Research, Inc, pp. 1-7.

Grossman, S. J., Hart, O. D., 1986. The costs and benefits of ownership: A theory of vertical and lateral integration. Journal of Political Economy 94 (4), 691-719.

Haeussler, C., Higgins, M., 2014. Strategic alliances: Trading ownership for capabilities. Journal of Economics \& Management Strategy 23 (1), 178-203. 
Hart, O. D., Moore, J., 1990. Property rights and the nature of the firm. Journal of Political Economy 98 (6), 1119-58.

Hassid, J., 1975. Recent evidence on conglomerate diversification in U.K. manufacturing industry. The Manchester School of Economic and Social Studies 43 (4), 372-95.

Horn, H., Wolinsky, A., 1988. Worker substitutability and patterns of unionisation. The Economic Journal 98 (391), 484-497.

Hu, H. T., Black, B., 2007. Hedge funds, insiders, and the decoupling of economic and voting ownership: Empty voting and hidden (morphable) ownership. Journal of Corporate Finance 13 (2-3), 343-367.

Hubbard, R. G., Palia, D., 1995. Benefits of control, managerial ownership, and the stock returns of acquiring firms. RAND Journal of Economics 26 (4), 782-793.

Ichiishi, T., 1993. The cooperative nature of the firm. Cambridge University Press, Cambridge.

Jacquemin, A. P., Berry, C. H., 1979. Entropy measure of diversification and corporate growth. The Journal of Industrial Economics 27 (4), 359-369.

Kloyer, M., 2011. Effective control rights in vertical R\&D collaboration. Managerial and Decision Economics 32, 457-468.

Legros, P., Newman, A. F., 2014. Contracts, ownership, and industrial organization: Past and future. Journal of Law, Economics and Organization 30 (suppl_1), i82-i117.

Monderer, D., Samet, D., 2002. Variations on the Shapley Value. In: Aumann, R., Hart, S. (Eds.), Handbook of Game Theory with Economic Applications, 1st Edition. Vol. 3. Elsevier, Ch. 54, pp. 2055-2076.

Morck, R., Shleifer, A., Vishny, R. W., 1990. Do managerial objectives drive bad acquisitions? Journal of Finance 45 (1), 31-48. 
Owen, G., 1972. Multilinear extensions of games. Management Science 18 (5-Part-2), 64-79.

Palepu, K., 1985. Diversification strategy, profit performance and the entropy measure. Strategic Management Journal 6 (3), 239-255.

Prange, C., Mayrhofer, U., 2015. Alliances and joint ventures. Post-print, HAL.

Rosenbaum, P. R., Rubin, D. B., 1983. The central role of the propensity score in observational studies for causal effects. Biometrika 70 (1), 41-55.

Segal, I., 2003. Collusion, exclusion, and inclusion in random-order bargaining. The Review of Economic Studies 70 (2), 439-460.

Stigler, G. J., 1950. Monopoly and oligopoly by merger. The American Economic Review $40(2), 23-34$.

Stole, L. A., Zwiebel, J., 2008. Mergers, employee hold-up, and the scope of the firm: An intrafirm bargaining approach to mergers. See http://ssrn.com/abstract=2396077 or http://dx.doi.org/10.2139/ssrn.239607763.

Weber, R. J., 1988. Probabilistic Values for Games. The Shapley Value: Essays in Honor of Lloyd S. Shapley (Cambridge University Press: Cambridge), pp. 101-119.

Wernerfelt, B., Montgomery, C. A., 1988. Tobin's q and the importance of focus in firm performance. The American Economic Review 78 (1), 246-250. 


\section{Appendix A. Sample characteristics of top four Business Sectors}

Table 9 below shows that most of firms engaged in M\&A and JV contracts operate in the sector of Professional, Scientific and Technical Services (NAICS 3-digit code 541). In the group of M\&As, the average ROA is negative $(-2.25 \%)$ and the partners' complementarity degree (computed in the pre-integration year) is very high, on average it takes a value of 0.70 . In the group of JVs the average performance is still negative but the partners' complementarity index is very low, only 0.09. Looking at the MS contracts, the largest number of firms belong to the Sector of Financial activities (NAICS 3-digit code 523). These firms perform much better (the ROA is $+1.42 \%$ on average) and the complementarity degree is still very low, only 0.01 .

Table 9: Sample characteristics of top four Business Sectors* by number of integration contracts (average values in the pre-integration year).

\begin{tabular}{|c|c|c|c|c|c|}
\hline \multicolumn{6}{|c|}{$M \& A$} \\
\hline Sectors: & 541 & 524 & 561 & 522 & All \\
\hline No. of firms & 132 & 26 & 25 & 21 & 6 \\
\hline$C O M P_{i, j}^{t}$ & 0.700 & -0.200 & 0.0900 & 0.080 & 0.100 \\
\hline ROA & -2.25 & -0.65 & -1.18 & -4.07 & -1.70 \\
\hline Employees & 160 & 80 & 121 & 170 & 305 \\
\hline \multicolumn{6}{|c|}{$M S$} \\
\hline Sectors: & 523 & 334 & 541 & 561 & All \\
\hline No. of firms & 2587 & 577 & 569 & 308 & 89 \\
\hline$C O M P_{i, j}^{t}$ & 0.010 & 0.040 & 0.080 & 0.090 & 0.020 \\
\hline ROA & 1.42 & 9.45 & 2.35 & 2.57 & 3.30 \\
\hline Employees & 6345 & 751 & 1037 & 152 & 11580 \\
\hline \multicolumn{6}{|c|}{$J V$} \\
\hline Sectors: & 541 & 325 & 523 & 531 & All \\
\hline No. of firms & 111 & 86 & 84 & 72 & 16 \\
\hline$C O M P_{i, j}^{t}$ & 0.090 & 0.002 & 0.001 & 0.200 & 0.050 \\
\hline ROA & -2.78 & 2.84 & 1.13 & 1.67 & 1.80 \\
\hline Employees & 103 & 2078 & 298 & 91 & 1957 \\
\hline
\end{tabular}

* NAICS 2007 3-digit codes. See table 10 below for Sector definitions.

These data support the main insight of section ㄴ basically, small and less performing 
firms choose M\&A contracts, probably in hopes of getting an increase in size and productivity through highly complementary partners. On the contrary, the partner's complementarity seems to be a minor issue for larger and more efficient firms choosing MS or JV.

Table 10: Naics 2007 2- and 3-digit top four Business Sector definitions.

\begin{aligned} & \hline Sector Definition \\ & \hline $31-33$ Manufacturing \\ & 325 Chemical Manufacturing \\ & 334 Computer and Electronic Product Manufacturing \\ & 52 Finance and Insurance \\ & 522 Credit Intermediation and Related Activities \\ & 523 Securities, Commodity Contracts, and Other Fin. Inv. and Related Activities \\ & 524 Insurance Carriers and Related Activities \\ & 53 Real Estate and Rental and Leasing \\ & 531 Real Estate \\ & \hline $54-541$ Professional, Scientific, and Technical Services \\ & \hline 56 Administrative and Support and Waste Management and Remediation Services \\ & 561 Administrative and Support Services \\ & \hline\end{aligned}

\section{Appendix B. Data}

Sources: Bureau van Dijk $(B V D)$ Databases Orbis and Zephyr and own calculations based on I-O Tables for US $(I O)$.

\section{B1. Regressions and average treatment effects in section 5}

ROA, $B V D$ : Quarterly net income annualized, and then divided by total assets. Significant negative or persistently low returns suggest financial weakness.

Sales, $B V D$ : The dollar volume of transactions involving company products and services net of returns, allowances and sales discounts (net sales).

Employment, $B V D$ : Number of employees.

Treated "T", Dummy variable: BVD: 1 if deal completed (M\&A, MS or JV) where deals are mutually exclusive.

Profitability condition "PC", Dummy variable: $I O: 1$ if one of the following conditions is satisfied: 
- condition (5) for M\&A

- condition (8) for MS

- condition (12) for JV

where M\&A, MS and JV contracts are mutually exclusive.

Partners' complementarity index "COMP $P_{i, j}^{t}$ ", IO: defined by formula (14).

Complementarity index between partner $i$ and all third parties, $k$ " $C k i$ " ", IO: defined by formula (15).

Complementarity index between target $j$ and all third parties, $k$ " $\mathrm{Ckj} j^{t ",} \mathrm{IO}$ : defined by formula in footnote 11 .

\section{B2. Sample and pre-treatment characteristics (section 4 and subsections 5.1 , $5.3)$}

EBIT, $B V D$ : Earnings before interest and taxes, is a measure of a firm's profit that includes all expenses except interest and income tax expense.

Total assets, $B V D$ : The total of all assets owned by a company. These things might be liquid assets such as cash and short-term investments, physical assets such as buildings, trucks, inventories of products and equipment or intangible assets such as goodwill, trademarks and patents.

Deal value, $B V D$ : is essentially the price that one party will pay for the other, or the value that one side will give up to make the transaction work.

Enterprise value, $B V D$ : is a measure of a company's total value, often used as a more comprehensive alternative to equity market capitalization. The market capitalization of a company is simply its share price multiplied by the number of shares a company has outstanding. Enterprise value is calculated as the market capitalization plus debt, minority interest and preferred shares, minus total cash and cash equivalents. 
Fixed assets, $B V D$ : are a long-term tangible piece of property that a firm owns and uses in the production of its income and is not expected to be consumed or converted into cash any sooner than at least one year's time. Fixed assets are sometimes collectively referred to as "plant". Fixed assets can include buildings, computer equipment, software, furniture, land, machinery and vehicles.

Cash flow, $B V D$ : is the net amount of cash and cash-equivalents moving into and out of a business. Positive cash flow indicates that a company's liquid assets are increasing, enabling it to settle debts, reinvest in its business, return money to shareholders, pay expenses and provide a buffer against future financial challenges.

Gross profit, $B V D$ : is the proportion of money left over from revenues after accounting for the cost of goods sold, where cost of goods sold represents the cost of materials, labor and factory overhead needed to bring to a marketable state the goods that have been sold.

Operating revenue turnover, $B V D$ : is the revenue a company receives in the course of its normal operations. Examples include sales and commissions, as well as other things that may vary according to the time of business revenue.

Value added, $B V D$ : describes the enhancement a company gives its product or service before offering the product to customers. Value-added applies to instances where a firm takes a product that may be considered a homogeneous product, with few differences (if any) from that of a competitor, and provides potential customers with a feature or add-on that gives it a greater sense of value.

Return On Shareholders Funds (ROSF), BVD: is a measure of the profit for the period which is available to the owner's stake in a business, therefore is a measure of profitability. Industry investors quote the ROSF ratio as a percentage. ROSF is calculated as: $\mathrm{ROSF}=(($ Net profit after taxation $\&$ preference dividend $) /($ Ordinary share capital + Reserves)) x 100. 